\title{
Retinopathy of Prematurity in Zone 2
}

National Cancer Institute

\section{Source}

National Cancer Institute. Retinopathy of Prematurity in Zone 2. NCI Thesaurus. Code C99045.

Retinopathy of prematurity located in zone 2 of the retina. 